\title{
The disarrayed mutation results in cell cycle and neurogenesis defects during retinal development in zebrafish Lisa M Baye and Brian A Link*
}

\author{
Address: Department of Cell Biology, Neurobiology, and Anatomy, Medical College of Wisconsin, Milwaukee, WI 53226, USA \\ Email: Lisa M Baye - lbaye@mcw.edu; Brian A Link* - blink@mcw.edu \\ * Corresponding author
}

Published: 5 April 2007

BMC Developmental Biology 2007, 7:28 doi:10.1/86/147|-2।3X-7-28

This article is available from: http://www.biomedcentral.com/l47|-2/3X/7/28

(C) 2007 Baye and Link; licensee BioMed Central Ltd.

This is an Open Access article distributed under the terms of the Creative Commons Attribution License (http://creativecommons.org/licenses/by/2.0), which permits unrestricted use, distribution, and reproduction in any medium, provided the original work is properly cited.
Received: 8 November 2006

Accepted: 5 April 2007

\begin{abstract}
Background: The vertebrate retina is derived from proliferative neuroepithelial cells of the optic cup. During retinal development, cell proliferation and the processes of cell cycle exit and neurogenesis are coordinated in neuroepithelial progenitor cells. Previous studies have demonstrated reciprocal influences between the cell cycle and neurogenesis. However the specific mechanisms and exact relationships of cell cycle regulation and neurogenesis in the vertebrate retina remain largely unknown.
\end{abstract}

Results: We have isolated and characterized a zebrafish mutant, disarrayed $\left(\right.$ dry $\left.^{a 64}\right)$, which exhibits retinal defects in cell cycle regulation and neurogenesis. By 42 hours post fertilization, disarrayed mutants show small eyes and a reduced forebrain. Other aspects of development appear normal. Although retinogenesis is delayed, mutant retinal cells eventually differentiate to all major cell types. Examination of the disarrayed mitotic cycle using $\mathrm{BrdU}$ and direct imaging techniques revealed that retinal neuroepithelial cells have an extended cell cycle period and reduced rate of cell cycle exit and neurogenesis, despite the fact that neurogenesis initiates at the appropriate time of development. Genetic mosaic analyses indicate that the cell cycle phenotype of disarrayed is cellnon-autonomous.

Conclusion: The disarrayed mutant shows defects in both cell cycle regulation and neurogenesis and provides insights into the coordinated regulation of these processes during retinal development.

\section{Background}

Regulation of the cell cycle is important for every organism during development, both at the level of controlling the total cell number as well as producing of the correct ratio of cell types. This is especially true for the development of the highly ordered, laminar retina. The vertebrate retina develops from a pseudostratified multipotent neuroepithelium from which all seven cell classes differentiate [1-3]. The neurons of the differentiated retina are organized into three layers that form synapses in two plexiform strata [4]. The inner most layer, the ganglion cell layer, consists primarily of ganglion cells while the middle inner nuclear layer is comprised of amacrine, bipolar, horizontal and Müller glial cells. The outer nuclear layer contains rod and cone photoreceptors and is adjacent to the retinal pigmented epithelium.

During retinal development, cell cycle regulation and neurogenesis are tightly linked by developmental time and through reciprocal influences [5]. The first cells to exit 
the cell cycle are ganglion cells, followed by distinct but temporally overlapping waves of differentiating inner and outer nuclear layer cells [6-8]. Both intrinsic and extrinsic cellular mechanisms have been shown to be important for regulating cell cycle exit and neurogenesis in the nervous system, but the relative importance of each is not well understood $[5,9,10]$. For example, the transcription factor Ath5 is expressed in a wave-like fashion across the neuroepithelium, immediately proceeding cell cycle exit and differentiation of ganglion cells [11-13]. Ath5 expression has been shown to be regulated by intrinsic mechanisms as well as through extrinsic cues $[14,15]$. Loss- and gainof-function studies have shown that Ath5 is necessary for ganglion cell genesis, but not sufficient to force progenitor cells out of the cell cycle [16-18]. These observations suggest that additional pathways are required for promoting cell cycle exit and neurogenesis. In addition, other investigators have shown that mechanisms that regulate the cell cycle have direct influence on neurogenesis [9,18-23]. For example, selectively lengthening G1-phase of the cell cycle in cortical progenitor cells promotes cell cycle exit and neurogenesis $[21,22]$. Furthermore, Calegari et al., 2005 have shown that neuroepithelial cells committed to divide neurogenically, where at least one daughter cell withdraws from the mitotic cycle, have longer cell cycle periods than progenitors that will remain symmetrically proliferative [23]. These data depict the complex interactions that regulate the cell cycle and neurogenesis, as well as exemplify the direct effects that the cell cycle has on neurogenesis.

Here we report the phenotypic analysis of the disarrayed mutation which exhibits defects in cell cycle regulation and neurogenesis in the developing retina. Histological and cell marker analyses reveal that although the retina is small and differentiation is delayed, all cell types are generated. In mutant retinal cells, expression of the proneural factor Ath5 and the early post-mitotic neuronal marker $\mathrm{HuC}$ initiate on time; however, the cell cycle period is extended and the proportion of progenitors that exit the cell cycle is reduced. Interestingly, genetic mosaic studies show that disarrayed is cell-non-autonomous for defects in cell cycle withdrawal. Our data suggest that the disarrayed gene product has an essential role in regulation of the cell cycle in retinal neuroepithelia. In addition, analysis of this mutant offers insights into extrinsic influences and the relationships between cell cycle regulation and neurogenesis during retinal development.

\section{Results}

The disarrayed mutation delays retinal histogenesis, but is not essential for cell-type fate determination

The disarrayed mutant was identified as a recessive lethal mutation from an ENU mutagenesis screen for retinal development phenotypes [24]. Mendelian inheritance in multiple genetic backgrounds strongly suggest the disarrayed mutation is caused by alterations to a single locus. Mutant embryos can be identified at 42 hours post fertilization (hpf) by small eyes and forebrain when compared to wild-type siblings (Fig. 1A). Other aspects of development appear normal including body size and shape, otic vesicles, heart formation, pigmentation, and touch responses; however, a swim bladder does not form and mutant larvae die between 8 to 12 days post fertilization (dpf).

Histology revealed that retinal lamination was significantly delayed in disarrayed mutants, but layer formation eventually developed (Fig. 1). For example, by $48 \mathrm{hpf}$, wild-type embryos have established the inner plexiform layer while synapse formation in the inner plexiform layer of disarrayed embryos was just initiating in the ventralmost region of the retina (Fig. 1B,C). As development continued, mutant eyes showed morphological differentiation for all the retinal cells types and formed the inner and outer plexiform layers by $96 \mathrm{hpf}$ (Fig. 1D-G). Although photoreceptors were generated and positioned in the correct location, differentiation was discontinuous and outer segment formation appeared abnormal and stunted. Lens growth and other aspects of ocular anterior segment morphogenesis were normal in mutants.

To confirm cellular differentiation and correct laminar positioning, markers for specific retinal cell-types were analyzed. Antibodies that recognize ganglion cells, amacrine cells, and cone photoreceptors, retinal cells from all three layers, showed differentiation and appropriate laminar positioning in disarrayed (Fig. 2A-D). Analysis of markers for other cell-types also showed appropriate celltype patterning. These studies included mRNA in situ hybridizations for $v s x-2$ (bipolar cells), c-ret (amacrine and horizontal cells) and rhodopsin, ultra violet, blue, red, and green opsins (rod and cone photoreceptors) (data not shown). Furthermore, immunoreactivity for SV2, a synaptic vesicle marker, showed accumulation in the inner plexiform layer of both wild-type and disarrayed retinas. However, the outer plexiform layer in mutants showed significantly reduced staining. This reduction of SV2immunoreactivity in the outer plexiform layer is consistent with the observed photoreceptor dysmorphogenesis. Overall, histological and marker analyses demonstrated that although significantly delayed, cell-type determination, laminar patterning, and synaptogenesis occur in the disarrayed retina.

\section{The disarrayed mutation causes defects in cell proliferation}

To examine the basis of the small eye phenotype and delay in retinal development for disarrayed embryos, we investigated the proliferative state and timing of neuro- 

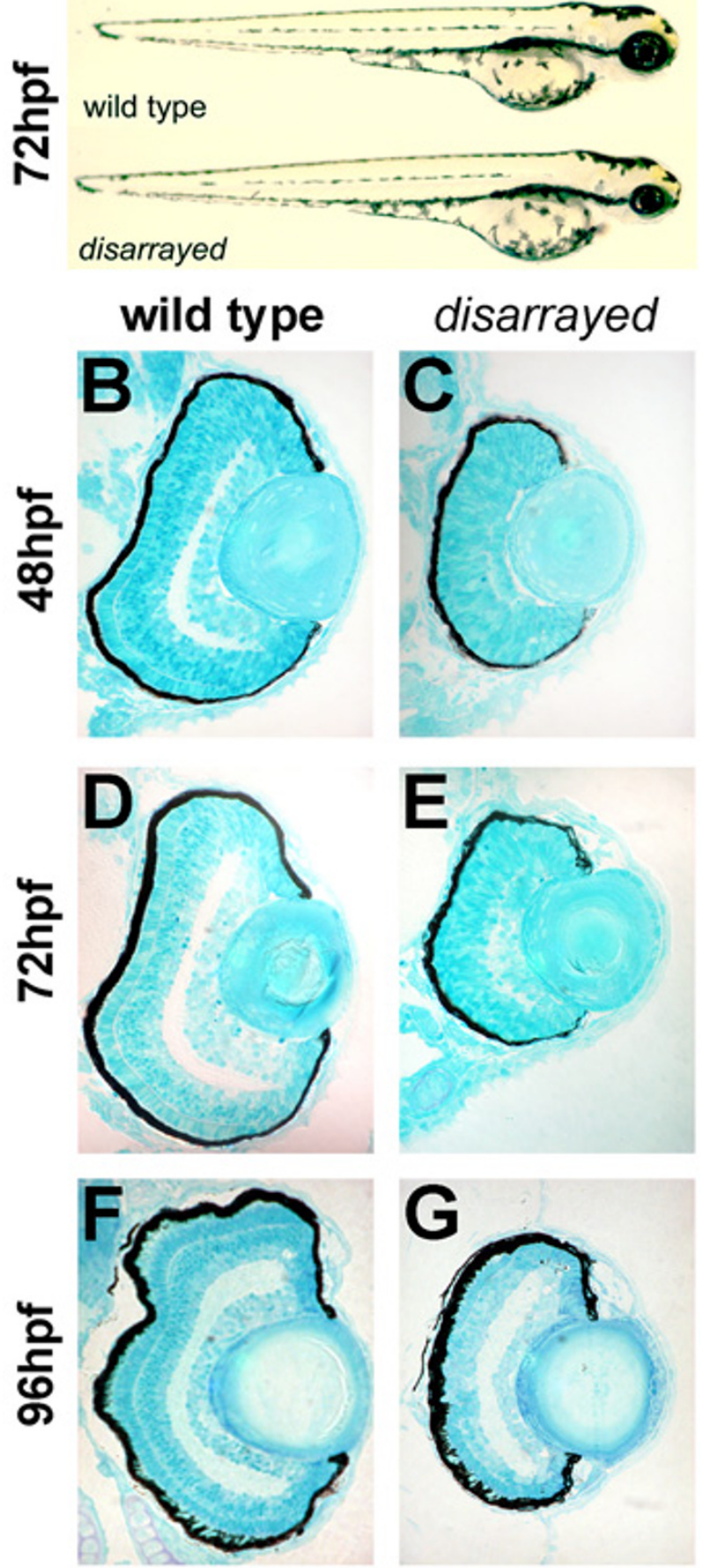

Figure I

Delayed retinal lamination in disarrayed eyes. $(A)$ Lateral views of wild-type (upper) and disarrayed (lower) sibling embryos at 72 hpf. Mutant embryos are characterized by smaller eyes and forebrain by $42 \mathrm{hpf}$. Transverse central retinal sections of wild-type (B,D, F) and disarrayed (C,E,G) at 48 hpf (B,C), 72 hpf (D,E), and 96 hpf $(F, G)$. Note the significant delay in differentiation and lamination in the disarrayed retina, although lens growth appears normal.

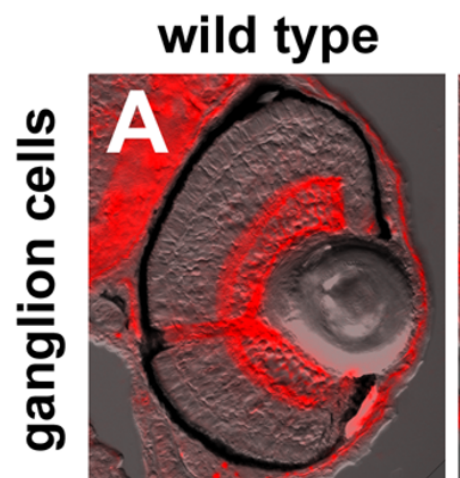

\section{disarrayed}
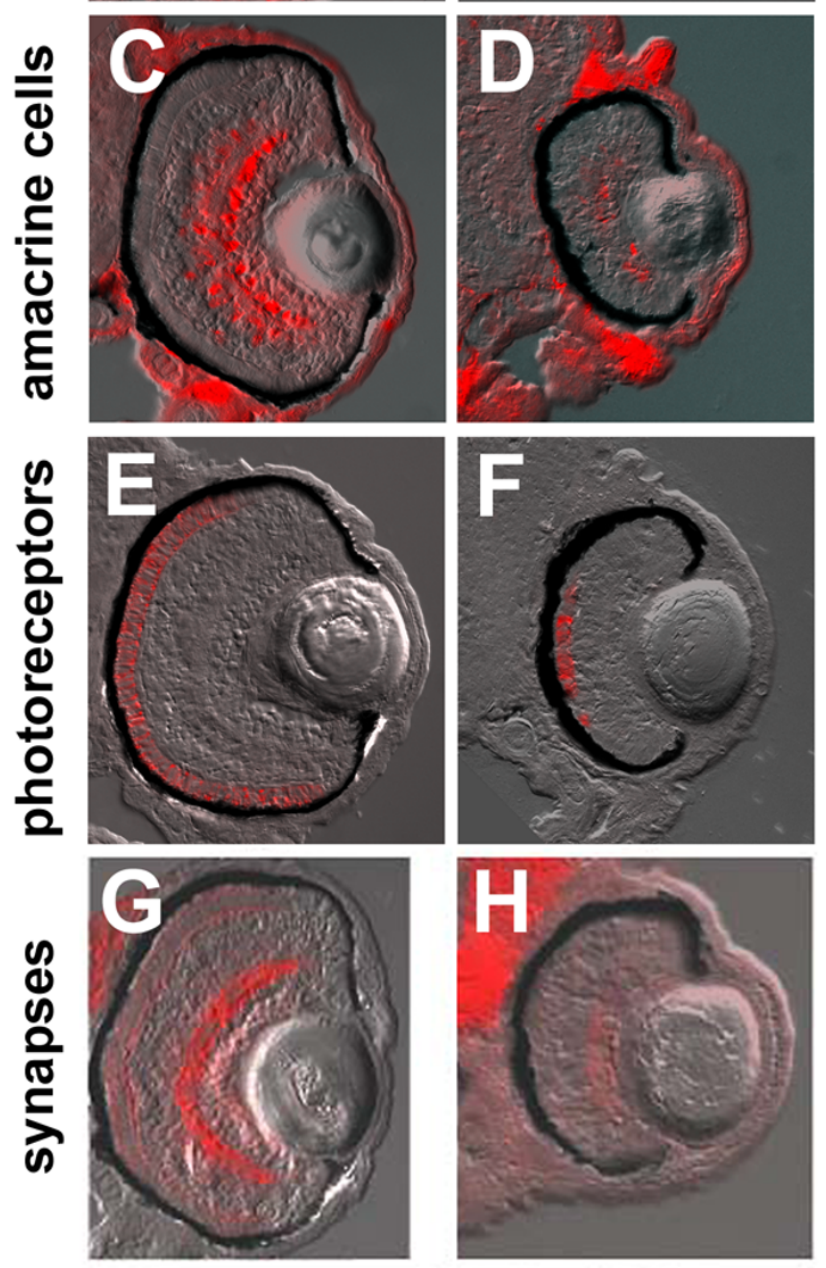

Figure 2

Retinal cell-type marker analysis in disarrayed eyes. Transverse central retinal sections from $96 \mathrm{hpf}$ wild-type $(A, C, E, G)$ and disarrayed (B,D,F,H) embryos assessed for celltype and lamina specific markers. $(A, B)$ Immunofluorescence for zn8 antigen (retinal ganglion cells and their axons); (C, D) parvalbumin (amacrine cells and their processes); (E,F) zpr I antigen (cone photoreceptor cells); and (G,H) SV2 antigen (synaptic vesicles). All cell types are present and in the correct laminar position. All figures are bright field images overlaid with the immunofluorescent label. 
genesis. To assess the proliferative state of mutant cells, the S-phase marker 5-bromo-2'- deoxyuridine (BrdU) was utilized. BrdU was injected into wild-type or mutant embryos, 1 hour prior to fixation, at three developmental time points: 48, 72 and $96 \mathrm{hpf}$. This method labels all cells that are in S-phase and therefore will mark proliferative progenitor cells. In wild-type embryos, retinal neuroepithelial cells begin exiting the cell cycle at $28 \mathrm{hpf}$ and by 96 hpf the majority of mitotic cells are restricted to the marginal zone, an area that remains proliferative for the life of the fish $[8,25]$ (Fig. 3A). In contrast to wild-type retina, disarrayed retina showed BrdU-positive cells in the central region at $48 \mathrm{hpf}$. Proliferative cells in mutant eyes were not restricted to the marginal zone until $96 \mathrm{hpf}$ (Fig. 3A). Even at this relatively late time point, the proliferative marginal zone was expanded (Fig. 3Avi). To quantify these findings, we scored the percent of total retinal cells that were BrdU-positive at each developmental time (Fig. 3B). This analysis revealed that at each age assessed, significantly more mutant cells were actively in S-phase as compared to wild-type retinas.

\section{Retinal neurogenesis initiates on time in disarrayed}

These observations with BrdU could be caused in part by delays in cell cycle exit and neurogenesis. In zebrafish and other vertebrates, expression of the proneural gene ath 5 marks cells competent to exit the cell cycle [26-28]. Expression of ath 5 mRNA in zebrafish begins at approximately $25 \mathrm{hpf}$ in the ventral nasal quadrant and spreads in a wave-like manner throughout the retina, preceding cell cycle exit and differentiation [13,17]. In situ hybridization revealed that ath 5 expression initiates on time in disarrayed retina (Fig. 4Ai, ii). However, the restriction of ath 5 mRNA to the peripheral retina is delayed in mutants. Wild-type embryos begin to show marginal zone restriction of gene expression by $60 \mathrm{hpf}$, whereas the mutants do not show restriction until $72 \mathrm{hpf}$ (Fig 4Av, viii). To ensure that cells that are expressing neurogenic markers have indeed exited the cell cycle we utilized the $\operatorname{Tg}($ atoh7:gfp) reporter line. These transgenic fish express GFP under regulator elements of the ath5 (atoh7) promoter [14,28,29]. In wild-type zebrafish retinal cells, ath5:GFP is expressed just preceding a symmetric neurogenic cell division in which both daughter cells leave the mitotic cycle [28]. Like, wild-type retinal progenitor cells, we observed that ath5:GFP progenitor cells in disarrayed retina were also BrdU-negative (Fig. 4B). However, the proportion of ath5:GFP cells in disarrayed retina was reduced. Together these data suggest that disarrayed neuroepithelial cells are competent to withdraw from the mitotic cell cycle, but are delayed in the process of neurogenesis.

To investigate whether terminal mitotic events initiate at the appropriate developmental time in mutant embryos, we analyzed the expression of the post-mitotic differenti- ation marker $h u c$. For these studies we utilized the transgenic line $\mathrm{Tg}$ (elav3:eGFP) which expresses enhanced green fluorescent protein (GFP) under the huc (elav3) promoter (huc:GFP) [30]. Expression of this transgene occurs approximately 3-5 hours following the terminal mitosis of ganglion and amacrine cells [24,31]. The huc:GFP transgene was bred onto the disarrayed background and the timing of cell cycle exit (GFP expression) was compared between wild-type and mutant embryos (Fig. 4C). As with ath5 expression, the initiation of terminal mitosis was similar in wild-type and disarrayed retinas.

\section{disarrayed retinal progenitor cells have an extended cell cycle}

Because neurogenesis initiates on time in the disarrayed retina, we investigated other possibilities for the increased incidence of proliferative cells noted from BrdU studies. Specifically, the disarrayed mutation may cause lengthening of the cell cycle period or changes in specific phases of the cell cycle. Alternatively, or additionally, disarrayed may affect the rate of neurogenesis (the proportion of cells withdrawing from the cell cycle), without changing cell cycle phase kinetics. To distinguish between these possibilities, we first estimated cell cycle period length and phase kinetics using the Cumulative BrdU Labeling and Labeled Mitoses techniques [32]. These methods provide estimates of the relative change in cell cycle kinetics between defined populations of cells, but alone cannot be used to accurately determine average phase-lengths in heterogeneous cell populations as each method biases estimates for the longest cell cycles in the population. We found that the maximum cell cycle period in disarrayed retinal progenitor cells was 2.27 fold longer compared to wild-type cells at 26 hpf. S-phase was 2.18 fold longer, while $\mathrm{G} 2+\mathrm{M}$ phases were increased by 1.42 times (Fig. 5A). In addition, $\mathrm{M}$-phase was assessed in disarrayed mutants by chromatin condensation and phosphoHistone-3 (pH3) immunoreactivity. Like wild-type retinal cells, M-phase always occurred at the apical surface suggesting that cell polarity was not disrupted (data not shown).

Quantization of nuclear size in proliferative neuroepithelia showed that with development the size of the nucleus decreases with ongoing cell division. (Fig. 5B). Consistent with reduced proliferation in disarrayed retinal progenitors, mutant nuclei were larger than the nuclei of wildtype siblings when compared at $48 \mathrm{hpf}$. However, at 24 hfp we found no change in the average size of the nuclei, suggesting that the proliferation defects in disarrayed mutants occur after this time in development. Interestingly, the timing of the cell cycle defect in disarrayed cells correlates with normal time of expansion of the retinal progenitor pool. In wild-type cells the increased rate of the cell cycle period begins at $24 \mathrm{hpf}$, following an extended 

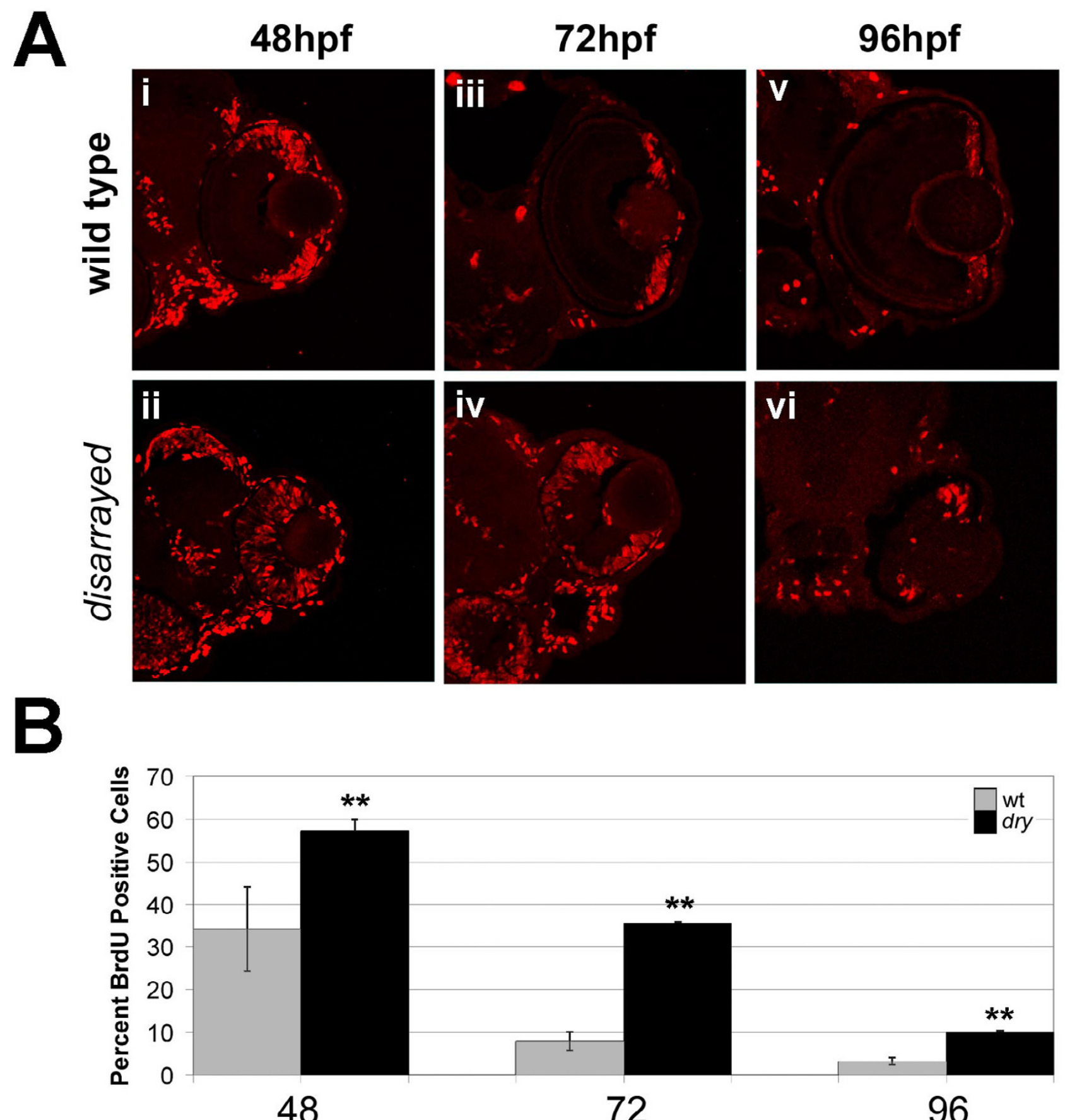

Hours Post Fertilization

\section{Figure 3}

Proliferation defects in disarrayed retinas. (A) One hour labeling with $\mathrm{BrdU}$ (red) at $48 \mathrm{hpf}$ (i, ii), $72 \mathrm{hpf}$ (iii, iv) and $96 \mathrm{hpf}$ $(\mathrm{v}, \mathrm{vi})$ in wild-type and disarrayed embryos. Wild-type proliferative cells are restricted to the marginal zone by $72 \mathrm{hpf}$, whereas the disarrayed retinal progenitors do not restrict to the marginal zone until $96 \mathrm{hpf}$. (B) Quantization of the one hour BrdUinjections presented as the percentage of BrdU-positive cells divided by total cell number at $48 \mathrm{hpf}, 72 \mathrm{hpf}$ and $96 \mathrm{hpf}$. ** $\mathrm{p} \leq$ 0.01 (Student's t-test). Grey bars, wild-type; black bars, disarrayed. Three central retinal sections were counted from three independent embryos for each time point. 

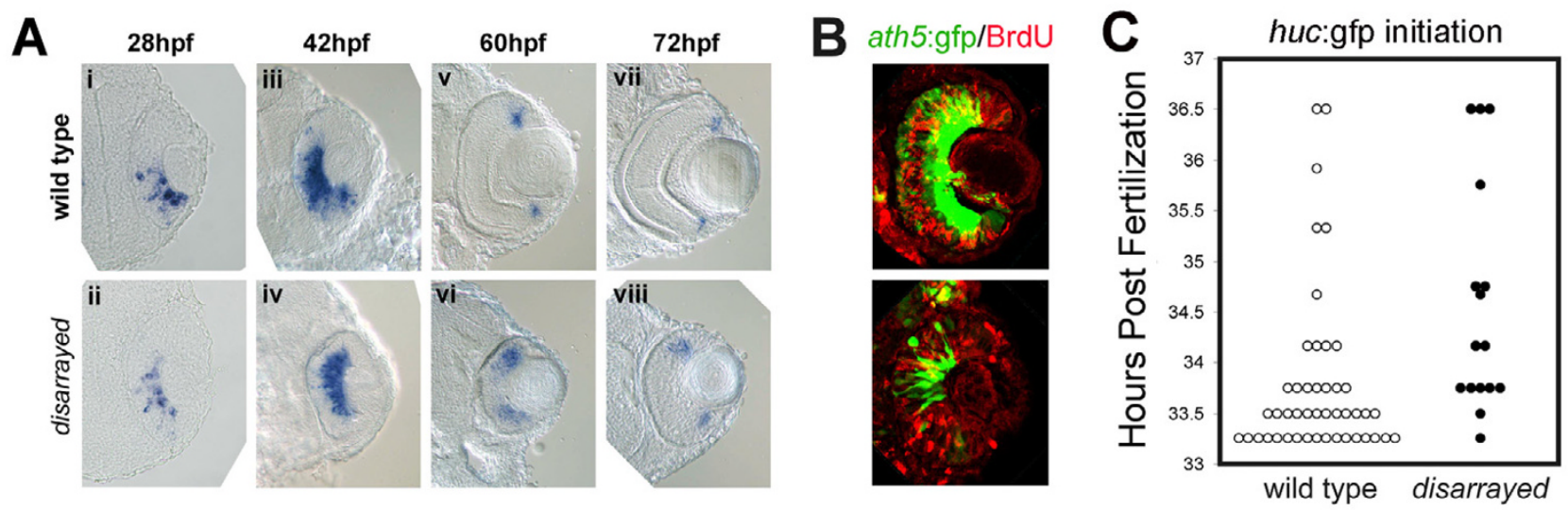

\section{Figure 4}

Initiation of retinal neurogenesis in disarrayed eyes. (A) In situ analysis of ath5 expression during retinogenesis in wildtype (i, iii, v, vii) and disarrayed eyes (ii, iv, vi, viii). (B) BrdU pulse-labeling (red) in wild-type (upper) or disarrayed (lower) embryos carrying the ath5:gfp transgene (green). Embryos were injected with BrdU at 36 hpf and fixed at 42 hpf. Note that in both genotypes, ath5:GFP expression in central retinal cells is post-S-phase. (C) Developmental time (hours post fertilization) for the initiation of huc:GFP expression. The initiation of GFP expression was recorded for all embryos at $0.5 \mathrm{hr}$ intervals in a clutch from an in-cross of disarrayed heterozygous parents (one circle represents one embryo; mutant (black circles) and wildtype (white circles)). Note that all embryos initiate huc:GFP expression within the same window of development. Results from one representative experiment $(n=16$ mutant and $n=45$ wild-type embryos from one clutch of embryos).

pause in proliferation to accommodate optic cup morphogenesis [35]. Overall, these analyses demonstrate that following optic cup morphogenesis, but before the initiation of neurogenesis, the cell cycle of disarrayed retinal progenitors dramatically slows as compared to wild-type cells.

\section{Interkinetic nuclear migration is coordinated with the cell cycle in disarrayed mutants}

In addition, we assessed interkinetic nuclear migration, the oscillation of the nucleus within neuroepithelial cells that correlates with cell cycle progression. This behavior was investigated by time-lapse microscopy of Histone2B:GFP (H2B:GFP) labeled nuclei from either wild-type or disarrayed retina beginning at $26 \mathrm{hpf}$. Our analysis indicated that interkinetic nuclear migration occurred normally as nuclei moved in both the apical and basal directions and mitosis always occurred at the apical surface. However, interkinetic nuclear migration was slowed proportionately to the altered cell cycle of mutant cells (Additional files 1 and 2). In fact, we were not able to measure a full cell cycle for disarrayed progenitor cells during an average time-lapse experiment, indicating that in the shortest mutant cell cycles periods are $>16$ hours. In contrast, we routinely observe multiple rounds of cell divisions in wild-type cells during a 16 hour time-lapse experiment and found that the shortest cell cycles in wildtype progenitors were 4 hours. No elevation in cell death was noted at these early time points, in contrast to increased cell death found at later times as noted below.

To further quantitate the defects in interkinetic nuclear migration, we determined the average apical-to-basal and basal-to-apical velocities of individual nuclei. To do this we imaged nuclear migration every 3 minutes over one hour intervals between 24-28 hpf. For both directions of movement, we found nuclear migration was slower in mutants as compared to wild-type cells (Table 1). Moreover, mutant nuclei were significantly more likely to remain stationary during the one hour of imaging. These delayed nuclear movements are consistent with reports that cell cycle progression is coordinately regulated with interkinetic nuclear migration [33-35].

\section{disarrayed mutants show a reduced rate of neurogenesis}

To evaluate the rate of retinal progenitor cells leaving the mitotic cycle, we measured the proportion of cells that exited the cell cycle over a small window of developmental time. We analyzed the rate of cell cycle exit from 28-34 hpf, during the initial wave of neurogenesis and a time prior to the overt small eye phenotype in disarrayed embryos. This early time frame was chosen to avoid secondary phenotypes caused by a potential reduction of post-mitotic cell types, which can exert influence on retinal progenitor cell fates. Total cell counts of central retinal sections at $34 \mathrm{hpf}$ indicated that disarrayed eyes had nearly 


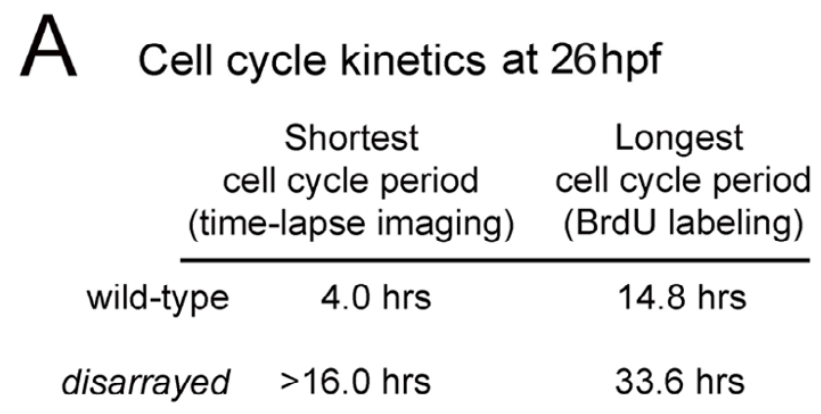

\begin{tabular}{rc} 
disarrayed fold increase \\
\hline total cell cycle & $2.27 x$ \\
S-phase & $2.18 x$ \\
G2/M-phase & $1.42 x$
\end{tabular}

D

Nucleus size

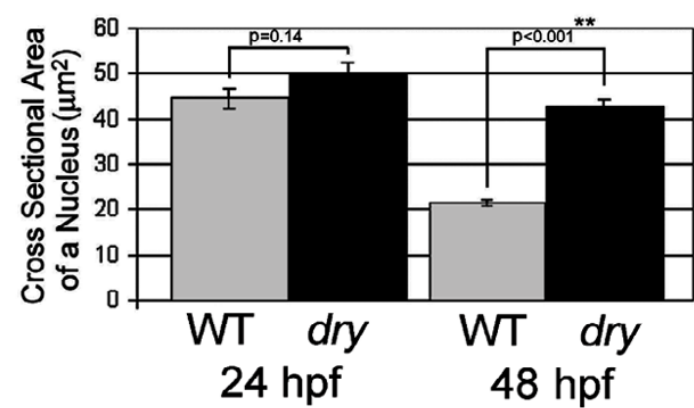

C

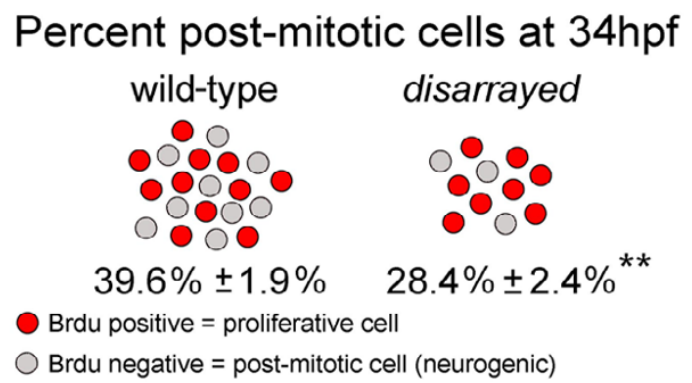

\section{Figure 5}

Extended cell cycle and reduced rate of retinal neurogenesis in disarrayed. (A) Cell cycle kinetics at $26 \mathrm{hpf}$ as determined using either direct time-laspse imaging or Cumulative BrdU Labeling with Labeled Mitosis methods. The total cell cycle period as well as S-phase and G2+M-phases were significantly extended at $28 \mathrm{hpf}$ in disarrayed retinas, as indicated by fold increase compared to wild-type siblings. (B) Nucleus size in wild-type (WT, grey) or disarrayed (dry, black) retinal progenitors at 24 and 48 hpf. (C) Comparison of the proportion of proliferative cells (red) to total cells (red + grey) which exited that cell cycle from 28-34 hpf in wild-type and disarrayed embryos. In mutant eyes there are fewer total cells $(216.2+/-8.4 \mathrm{vs}$. $383.1+$ +/ $-15.0 ; n=15$ and $n=14$ respectively) and a lower percentage that have exited the cell cycle by $34 \mathrm{hpf}$ (average $+/-\mathrm{SE}, \mathrm{n}=18$ $(\mathrm{WT})$ and $\mathrm{n}=\mathrm{II}(\mathrm{dry}))$. ** $\mathrm{p} \leq 0.00 \mathrm{I}$ (Student's t-test). 
Table I:

\begin{tabular}{lccccc}
\hline Phenotype & Direction of IKNM & $(\mathrm{n})$ & Percent of cells & Average Velocity $\mu \mathrm{m} / \mathrm{hr} \pm$ S.E.M. & St. Dev. \\
\hline Wild-type & $\mathrm{A} \rightarrow \mathrm{B}$ & $(20)$ & $54.1 \%$ & $8.3 \pm 1.4$ \\
disarrayed & $\mathrm{A} \rightarrow \mathrm{B}$ & $(30)$ & $49.2 \%$ & $4.8 \pm 0.4$ & 6.3 \\
Wild-type & $\mathrm{B} \rightarrow \mathrm{A}$ & $(14)$ & $37.8 \%$ & $27.1 \pm 6.9$ & $7.0 \pm 1.1$ \\
disarrayed & $\mathrm{B} \rightarrow \mathrm{A}$ & $(18)$ & $29.5 \%$ & - & 2.0 \\
Wild-type & no movement & $(3)$ & $8.0 \%$ & - & - \\
disarrayed & no movement & $(13)$ & $21.3 \%$ & - \\
\hline
\end{tabular}

SEM, Standard Error of the Mean; St. Dev, Standard Deviation; A, Apical; B, Basal; Percent of cells, Percent of total nuclei followed for each phenotype wild-type total $n=37$, disarrayed total $n=61$.

Student t-test values: WT vs disarrayed, $A \rightarrow B(p=0.026)$; WT vs disarrayed, $B \rightarrow A(p=0.013)$.

half $(216+/-5.5$ vs. $388+/-9.0)$ the total amount of cells that were present in wild-type sibling retinas (Fig. 5C). This significant reduction in the number of cells found in the disarrayed retina is most likely a direct result of the dramatic slowing of the cell cycle period. We tested this idea with long-pulse BrdU labeling to measure the proportion of cells which had exited the cell cycle during the initial phase of neurogenesis. At $34 \mathrm{hpf}$, $40 \%$ of the wild-type retinal cells had exited the cell cycle. In contrast, only $\sim 28 \%$ of the mutant cells had become post-mitotic (Fig. 5C). Together, these experiments indicate that the disarrayed phenotype is a result of both a lengthening of the cell cycle period and a reduction in the rate of neurogenesis.

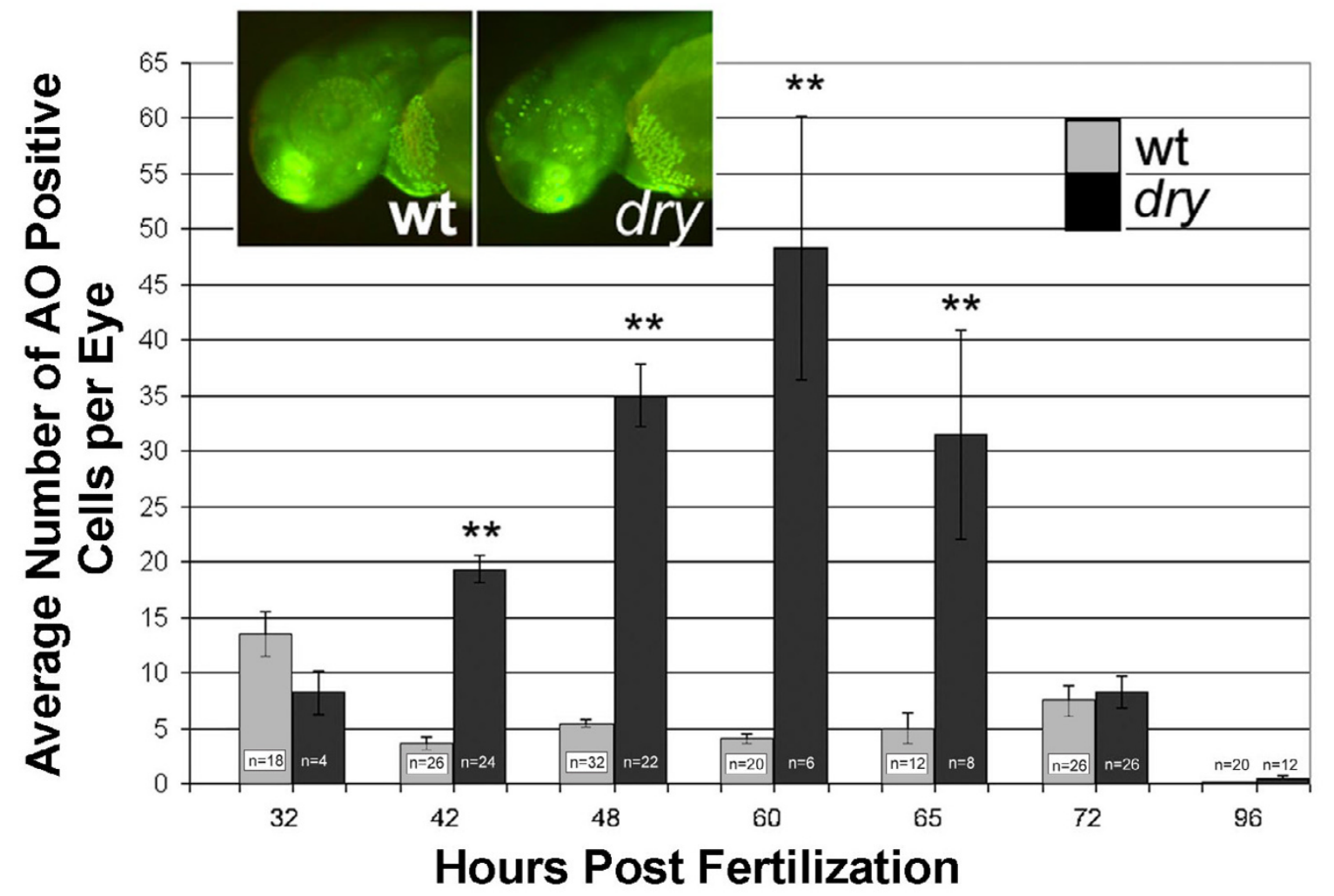

Figure 6

Elevated cell death in disarrayed retinas. Acridine orange (AO) was used to label dying cells in the living zebrafish embryo. The average number of positive cells per retina in wild-type (grey bars) and disarrayed embryos (black bars) is presented. Inset shows chromatin fluorescence (green) in wild-type (left) and disarrayed (right) embryos following acridine orange treatment at $48 \mathrm{hpf}$. Note that there are significantly more cells labeled in the disarrayed mutant retina and forebrain when compared to wild-type. ${ }^{* *} \mathrm{p} \leq 0.0$ I (Student's t-test). $\mathrm{n}=$ total number of embryos counted. 
Changes in the cell cycle often result in activation of apoptosis and increased cell death. Although time-lapse analysis did not show significant increases at early times of retinogenesis, later time points were not analyzed in those studies. We therefore, used an acradine orange labeling assay to more thoroughly evaluate retinal cell death throughout development [36]. Overall death in the developing zebrafish retina is normally very low (1-2\%) [37]. Mutant embryos, however, showed an increase in cell death beginning at $42 \mathrm{hpf}$ and peaking at $60 \mathrm{hpf}$. Cell death in mutant eyes returned to wild-type levels by 72 hpf (Fig. 6). Elevated cell death in the developing brain, particularly in the tectum, was also observed (Fig. 6 inset). However, no other obvious regions of increased cell death were observed in disarrayed embryos, suggesting that cell death is specific to regions of the developing nervous system. The increased cell death between 42-65 hpf may reflect activation of apoptosis due to cell cycle deregulation. Increased cell death certainly contributes to the obvious small eye phenotype at late stages of development.

\section{disarrayed functions cell-non-autonomously for cell cycle exit}

We next applied genetic mosaic analysis to examine the cellular autonomy of the disarrayed mutation with respect to the delay in neurogenesis. At $72 \mathrm{hpf}$ neurogenesis is complete in the central retina of wild-type embryos, whereas disarrayed eyes do not show complete morphological lamination until 96 hpf (Fig. 1D,G). Genetically mosaic retinas for both wild-type and disarrayed embryos were generated by transplantation of lineage labeled blastula stage cells [38]. The degree of mosaicism was controlled by varying the quantity of blastula cells transplanted. A range of 5-50 cells were transplanted into the eye-fated region of the blastula stage host embryos resulting in isolated clones in the retina. All genetic combinations of donor and hosts were generated and chimeric embryos were analyzed at $72 \mathrm{hpf}$. The genotype of donor cells was determined by phenotyping the donor embryos at $48 \mathrm{hpf}$. Wild-type cells transplanted into wild-type host embryos gave rise to mosaic clones in which lamination and morphology were normal (Fig. 7B). In contrast, disarrayed cells transplanted into disarrayed host embryos typically showed smaller clones of cells and were delayed in retinal differentiation (Fig. 7A). Importantly, when disarrayed cells were transplanted into wild-type host embryos, normal morphological differentiation was observed (Fig 7C). There were no changes in cell-type composition based on morphological differentiation between mutant cells and wild-type cells in wild-type host retinas (data not shown). Furthermore, when genetically wild-type cells developed in disarrayed mutant retinas, small clone sizes and delayed differentiation were most often observed (Fig 7D, dorsal half). However, when large mosaic patches were generated in disarrayed hosts, the wild-type donor cells devel- oped normally (Fig 7D, ventral half). Together, these data demonstrate that disarrayed functions cell-non-autonomously for morphological differentiation in the retina. The clone size dependence for morphological rescue suggests that disarrayed affects a local-acting soluble factor. From the genetic mosaic experiments, however, we could not address the source of the affected factor as it may be provided by the RPE, the lens, periocular mesenchyme, or within the retina itself.

To specifically address the cellular autonomy for the delay in retinal cell cycle exit within disarrayed eyes, we combined BrdU-labeling with genetic mosaic analysis. Mosaic retinas were generated as described above with the addition of a one hour pulse of BrdU at 60 hpf. This age was chosen because by 60 hpf in wild-type eyes, proliferative retinal cells are largely restricted to the marginal zone, while proliferative cells in disarrayed eyes are still found throughout the retina. Because we observed normal morphological differentiation of large wild-type clones that had been transplanted into the disarrayed hosts as described above, we only analyzed small, isolated clones of less than 20 cells in the retina for BrdU-labeling. All genetic mosaic combinations were generated. BrdU-labeling of donor cells in wild-type into wild-type chimeras showed $14.0 \%$ of the cells remained proliferative (Fig. $8 \mathrm{Ai}, \mathrm{B})$. When disarrayed donor cells developed in wildtype host retinas, 16.2\% remained BrdU-positive (Fig. 8 Aii, B). The number of proliferating cells was not significantly different between these two groups, indicating that disarrayed retinal cells are rescued for cell cycle exit by the wild-type environment. In contrast to cells in wild-type host environments, both disarrayed and wild-type donor cells in mutant retinas showed significantly more proliferative cells (Fig 8Aiii, Aiv, B). These data demonstrate that disarrayed functions non-cell-autonomously with respect cell cycle exit.

\section{Discussion}

The mechanisms underlying cell cycle regulation and neurogenesis in the developing nervous system are critical for generating the appropriate numbers and proportions of neurons. Through forward genetics, genes essential for these processes can be identified. We have isolated and characterized a recessive zebrafish mutation, disarrayed, which exhibits cell-non-autonomous defects in cell cycle regulation and neurogenesis.

In retinal development, the cell cycle is related to neurogenesis at several levels. Cell lineage studies and birth-dating analyses have shown that cell cycle exit and cell fate determination are tightly linked. The first cells to exit the cell cycle are ganglion cells which are followed by distinct but temporally overlapping waves of inner and outer nuclear layer cells [6-8]. From these observations, the 

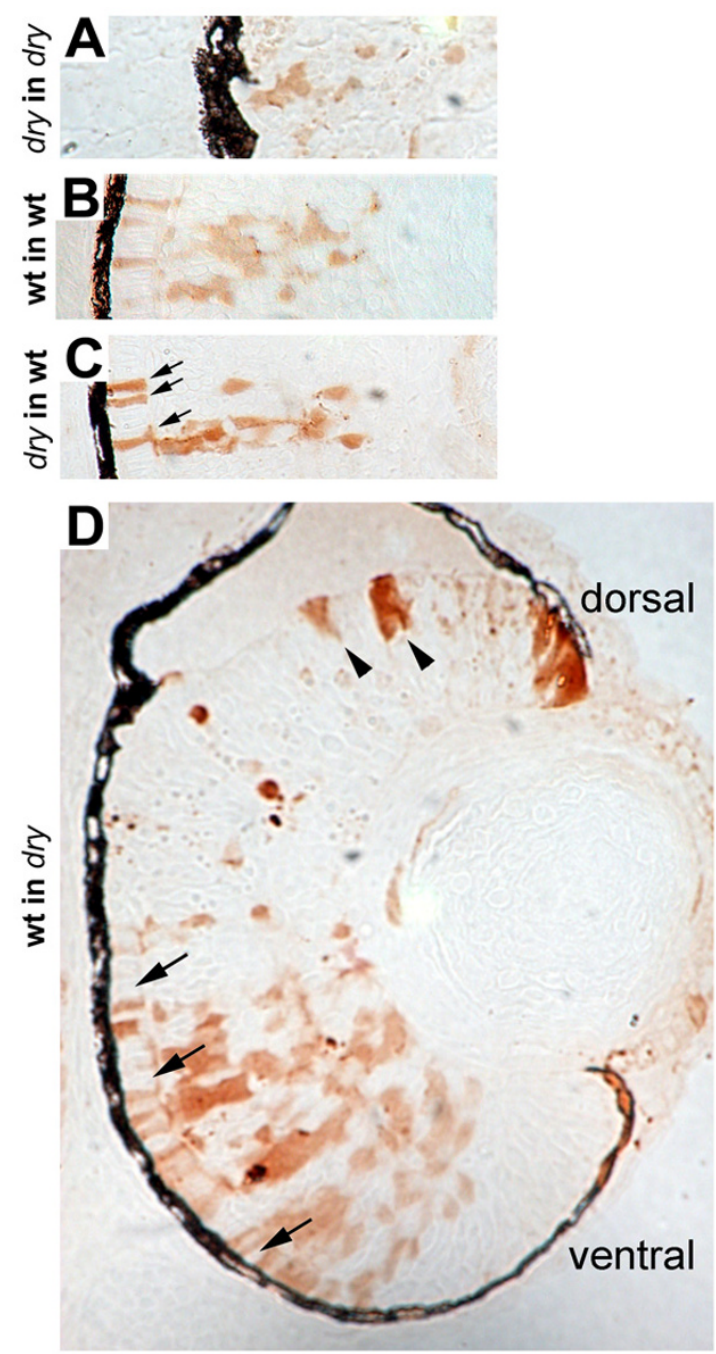

Figure 7

Genetic mosaic analysis of disarrayed retinal cells. Genetic mosaic retinas at 72 hpf where donor cells were lineage-labeled using biotin conjugated dextran (brown). (A) disarrayed mutant cells in a disarrayed mutant host embryo. Note reduced morphological differentiation and lamination of cells. (B) Wild-type cells in a wild-type host embryo. (C) disarrayed mutant cells in a wild-type host embryo. The disarrayed cells show wild-type morphology and lamination in the wild-type environment (compare B and C). For example, morphological rescue of photoreceptor elongation can be seen (C, arrows). (D) Wild-type cells in a disarrayed mutant embryo. Small wild-type cell clones resemble mutant cells as they appear delayed in morphological differentiation and lamination (dorsal, arrowheads). Wild-type cells in clones with greater donor mosaicism have normal morphological differentiation and rescue adjacent disarrayed mutant cells (ventral, arrows). The number of mosaic embryos examined: $n=2$ disarrayed into disarrayed, $n=5$ wild-type into wild-type, $n=9$ disarrayed into wild-type, $n=8$ wild-type into disarrayed. Each embryo contained multiple cell clones. competency model of retinal development has emerged. This model suggests that retinal progenitor cells irreversibly move through competency states where their developmental potential is restricted to produce only the cell type appropriate for that stage in development [6]. In vitro cell assays, cell transplantation experiments, and cell ablation studies indicate that competency is intrinsically determined, but is also influenced by changing signals from local microenvironments [10,39].

Mechanistically, proteins that regulate the cell cycle can also influence cell-type fate and differentiation pathways, and visa-versa $[9,20,40]$. For example the transcription factor Prox-1 is required for retinal progenitor cell proliferation, horizontal cell fate specification, and bipolar cell differentiation [41]. Over the course of neurogenesis, the cell cycle period increases among progenitor cells $[42,43]$. This is true within the retina as well as elsewhere in the developing nervous system [44]. The increase in cycle period also correlates with an increase in the proportion of progenitor cells leaving the mitotic cycle [23]. This observation has led to experiments to test whether the length of the cell cycle influences the probability of whether a neuronal progenitor cell leaves the mitotic cycle. In the cortex, several experiments have been conducted to lengthen the cell cycle and test this hypothesis. In general, all manipulations which lengthened the cell cycle period resulted in increased neurogenesis [21,22]. This is in striking contrast to disarrayed, in which the cell cycle of retinal progenitors is extended and the rate of cell cycle exit is significantly reduced, despite the fact that neurogenesis is initiated normally. This observation raises the question whether the duration of the cell cycle in retinal progenitors has the same influence on neurogenesis as it does in cortical progenitors. In a recent study investigating the influence of Hedgehog signaling on the cell cycle of Xenopus retinal progenitors, Locker et al. found that activation of this pathway quickens the cell cycle and promotes neurogenesis [45]. These researchers also showed that autonomously blocking Hedgehog signaling, via cyclopamine, lengthened the retinal progenitor cell cycle and reduced neurogenesis. Overall, these data suggest that differences exist between retinal and cortical progenitor cells in the role of the cell cycle during neurogenesis.

\section{Conclusion}

Although we do not know the gene affected by the disarrayed mutation, its unique phenotype has shed light on mechanisms of retinal development. First, our analysis of the cell cycle in disarrayed has provided insights into the relationship of cell cycle period and neurogenesis in the retina. Second, analysis of interkinetic nuclear migration in disarrayed corroborates other studies showing the oscillation of the nucleus within proliferative neuroepithelial cells is intimately linked with cell cycle progression [33- 

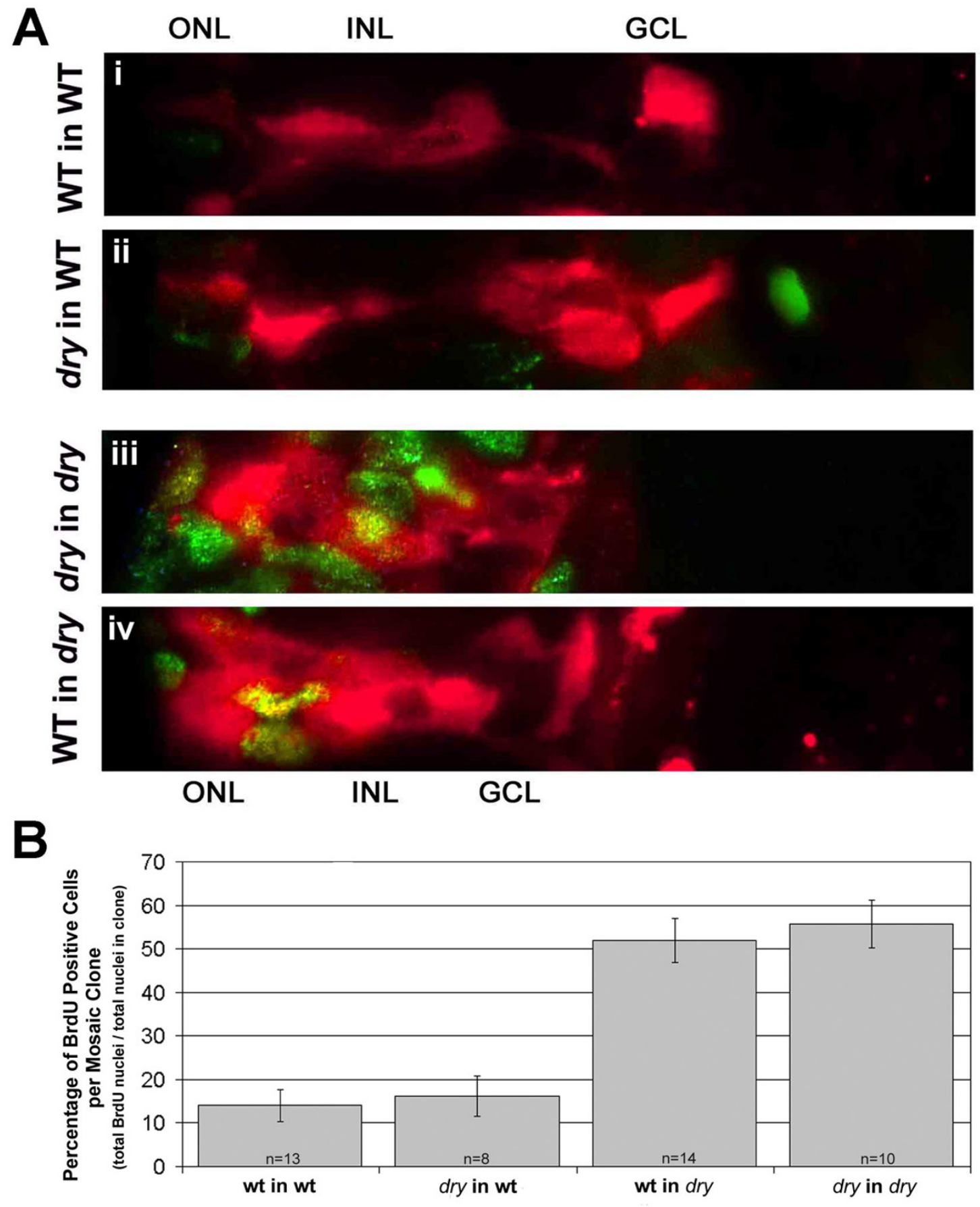

Figure 8

Defects in cell cycle exit for disarrayed are cell-non-autonomous. (A) Genetic mosaic retinas at $6 \mathrm{I}$ hpf where donor cells were lineage-labeled using rhodamine conjugated dextran (red). Chimeras were injected with BrdU for one hour at 60 hpf and processed for BrdU detection (green/yellow). Donor cells are shown in the outer nuclear layer (ONL), inner nuclear layer (INL) and ganglion cell layer (GCL) regions. Cells that are double labeled with the linage marker (red) and BrdU (green) appear yellow. (i) Wild-type cells in a wild-type host embryo. (ii)disarrayed cells in a wild-type host embryo. (iii) disarrayed cells in a disarrayed mutant host embryo. (vi) Wild-type cells in a disarrayed embryo. Note the increase in proliferative cells of wild-type or disarrayed genotype in mutant retinas (iii and iv, green/yellow cells). (B) Quantization of the percent of BrdU-positive cells within small (2-20 cells) mosaic clones. $\mathrm{n}=$ number of mosaic clones quantitated. 
35]. In these studies, we found nuclear migration in disarrayed neuroepithelial cells was slowed proportionately to the extended cell cycle period. Finally, the cell-non-autonomous activity of disarrayed may provide valuable information on the mechanisms of local-acting extrinsic influences that impact regulation of the cell cycle and neurogenesis during retinal development.

\section{Methods}

\section{Fish maintenance and stocks}

Zebrafish were maintained at standard conditions [46]. Embryos were staged by somite number and hours post fertilization (hfp) [47]. disarrayed is a recessive mutation that was isolated in an ENU mutagenesis screen for lamination mutants [24]. The disarrayed a64 allele was used for all experiments.

\begin{abstract}
Histology
Embryos were dechorionated and fixed in 1\% paraformaldehyde, $2.5 \%$ glutaraldehyde, $3 \%$ sucrose, $0.06 \%$ phosphate buffer ( $\mathrm{pH} 7.4)$ overnight at $4{ }^{\circ} \mathrm{C}$. The following morning, embryos were washed in $0.1 \mathrm{M}$ phosphate-buffered saline (PBS), dehydrated through an ethanol series and propylene oxide and then infiltrated with EMbed812/Araldyte 502 resin mixture. Semi-thin transverse sections, $1-2 \mu \mathrm{m}$ thick, were heat mounted on gelatin-coated glass slides and stained with 1\% methylene blue in 1\% borax. Images were captured using a Nikon coolpix 995 color digital camera mounted on a Nikon E800 compound microscope.
\end{abstract}

\section{Immunohistochemistry}

Embryos were fixed at four days post fertilization in 4\% paraformaldehyde/PBS overnight at $4{ }^{\circ} \mathrm{C}$. Following fixation, embryos were washed in PBS and processed for cryosection immunohistochemistry. Embryos were infiltrated at $4{ }^{\circ} \mathrm{C}$ in $15 \%$ sucrose, $30 \%$ sucrose, and overnight in $100 \%$ TBS (Triangle Biomedical Sciences). Embryos were then oriented in freezing molds and sectioned at $-25^{\circ} \mathrm{C}$. Twelve-micron cryosections were cut and mounted on gelatin-coated glass slides and then dried for $1-2$ hours at $25^{\circ} \mathrm{C}$. Slide edges were lined with a hydrophobic maker (PAP pen), washed with PBS and then blocked with 5\% normal sheep serum, $0.1 \%$ tween-20, $1 \%$ DMSO in PBS for 2 hours. Blocking solution was replaced with the primary antibody diluted in blocking solution and incubated overnight at $4{ }^{\circ} \mathrm{C}$. The next day slides were washed extensively in PBTD (PBS, 1\%DMSO, $0.1 \%$ Tween) and incubated for two hours at $25^{\circ} \mathrm{C}$ with Rhodamine-red X conjugated donkey anti-mouse secondary antiserum (Jackson ImmunoResearch Laboratories) diluted 1:800 in blocking solution. Slides were visualized on a Nikon E600FN compound microscope and imaged using a Photometrics coolSNAP camera with Metamorph Imaging software (Universal Imaging Corp, Philadelphia,
PA). The following primary antibodies were used: Zn8 (1:20), retinal ganglion cells and their axons (Provided by the Oregon Monoclonal Bank); Parvalbumin (1:200), amacrine cells and their processes (par19 clone, P-3088 from Sigma). ZPR1/FRET43 (1:40), cone photoreceptors (Provided by the Oregon Monoclonal Bank); synaptic vesicle protein 2 (SV2) (1:20), outer and inner plexiform layer synapses (Provided by the Oregon Monoclonal Bank).

\section{Acridine Orange Labeling}

Embryos were dechorionated at the appropriate developmental time points and placed in acridine orange solution $(5 \mu \mathrm{g} / \mathrm{ml}$ in embryo medium) (Molecular Probes, Eugene OR) for $30 \mathrm{~min}$ followed by extensive washes in embryo medium. Embryos were anesthetized and viewed under a fluorescence dissecting scope and the number of cells positively labeled with $\mathrm{AO}$ was determined. All embryos were grown in $0.003 \%$ 1-phenyl-2-thiourea (PTU) to block pigmentation and mediate visualization. Embryos that were 18 and 32 hpf were washed extensively after viewing and grown to $48 \mathrm{hpf}$ to phenotype and identify mutant embryos.

\section{BrdU Labeling}

To identify proliferative cells, BrdU-labeling was performed essentially as previously described [8]. Briefly, Sphase cells were identified over several developmental stages by injecting $10 \mathrm{mM}$ 5-bromo-2'- deoxyuridine in $1 \%$ phenol red into the yolk sac of anesthetized embryos. Embryos were allowed to integrate the BrdU for one hour and were then fixed with cold $4 \%$ paraformaldehyde/PBS overnight at $4{ }^{\circ} \mathrm{C}$. Following overnight fixation, embryos were processed for cyrosectioning as described above. Dried sections were washed in PBS and incubated with $400 \mu \mathrm{l}$ of a $20 \mathrm{U} / \mathrm{ml}$ DNAse I at $25^{\circ} \mathrm{C}$ for $30 \mathrm{~min}$ to facilitate immuno-detection of the incorporated BrdU. DNAse-treated sections were washed extensively in PBTD and processed for immuno-detection as previously described using a rat anti-BrdU antibody (Harlan Sera Labs MAS-250, diluted 1:1000 in blocking solution) and visualized using Rhodamine-red X conjugated donkey anti-rat secondary antiserum (Jackson ImmunoResearch Laboratories). The total cell population was labeled using the DNA dye Hoechst 33258 (Sigma). Three central retina sections from three embryos were counted to determine the ratio of BrdU positive cells over total nuclei. Images were captured using a Nikon C1 confocal microscope.

\section{Cell cycle kinetics}

Estimation of total cell cycle, S-phase and G1/M-phase length was determined by Cumulative BrdU Labeling and Labeled mitoses methods [21,32]. 
The Cumulative BrdU Labeling method utilizes multiple timed pulses of BrdU to label cells in S-phase in order to estimate the maximum total cell cycle period $(\mathrm{G} 1+\mathrm{S}+\mathrm{G} 2+\mathrm{M})$ and the length of S-phase. BrdU was injected into 26 hpf embryos, a time when all retinal cells are proliferative. Embryos were fixed at three time points after injection, 1.5, 3.25, and 5 hours. The ratio of BrdU positive cells to unlabeled cell was quantified for each time point and a linear regression was performed. The $\mathrm{X}$ intercept represents the estimated length of S-phase and the time value at $\mathrm{Y}=100$ estimates $\mathrm{G} 1+\mathrm{G} 2+\mathrm{M}[21]$.

The Labeled Mitoses method was combined with the time BrdU pulses described above. This technique involves quantifying the proportion of BrdU positive cells that are undergoing mitosis at each of the timed BrdU injections. Mitosis was defined by the condensation of chromatin as visualized by Hoechst nuclear staining. The ratio of BrdU positive to BrdU negative mitoses was determined and a best fit line determined. The value at $\mathrm{Y}=100$ estimates the length of $\mathrm{G} 2+\mathrm{M}[21]$. For all cell counts, one to three central retinal sections per eye were counted to determine the ratio of BrdU positive cells over total nuclei for both wildtype and disarrayed genotyped siblings. The number of eyes counted per time point were as follows: $1.5 \mathrm{hr}$, wt $n$ $=4$ and dry $n=7 ; 3.25 \mathrm{hr}$, wt $n=3$ and $d r y 5 ; 5 \mathrm{hr}$, wt $n=$ 4 and $d r y n=4$. Because this experiment was performed before the disarrayed phenotype was obvious, all embryos were PCR-genotyped using a tightly linked marker (see Genotyping).

\section{Genotyping}

A linked polymorphism was used to definitely determine embryo genotypes at developmental times before the disarrayed phenotype is obvious. Genotyping was preformed by polymerase chain reaction (PCR) using z-marker, z9233, which is closely linked to the disarrayed mutation (10 recombinations/1088 meioses). Following the PCR amplification, products were run on a $2 \%$ agarose gel. The primer set z9233 generates a single $\sim 225$ bp band for homozygous disarrayed mutants, a single 300 bp band for wild-type embryos and two bands for heterozygous embryos. For controls, the heterozygous parents and pooled genomic DNA from siblings that were phenotyped at $72 \mathrm{hpf}$ were also run on the gel.

\section{Assay to determine the rate of neurogenesis}

To determine the rate of neurogenesis, BrdU was provided to half of the embryos from a disarrayed heterozygous incross from 34 to $45 \mathrm{hpf}$. This pulse will label all proliferative progenitor cells. Cells which are not labeled, therefore, were post-mitotic at $34 \mathrm{hpf}$. The remaining embryos were fixed at $34 \mathrm{hpf}$, genotyped as described above, and total central retinal cell numbers were scored. Cell counts at $34 \mathrm{hpf}$ or $45 \mathrm{hpf}$ were performed by averaging three central retina sections per retina at each age. Because neurogenesis initiates at $\sim 29 \mathrm{hpf}$ in both mutant and wildtype embryos, the proportion of post-mitotic (BrdU-negative) to total cell numbers for each genotype estimates the rate of neurogenesis. Note this technique will provide a comparative evaluation of the rate of neurogenesis irrespective of cell cycle period.

\section{Quantification of nuclear size}

Nuclei of retinal progenitor cells were labeled by breeding the disarrayed mutant fish into the $\mathrm{Tg}(\mathrm{h} 2 \mathrm{afz}$ :GFP)kca6 transgenic line which expresses the nuclear localized GFP in all cells [48]. All embryos were grown in $0.003 \% 1$-phenyl-2-thiourea (PTU) to block pigmentation. At 24 and 48 hpf, labeled embryos were anesthetized with $0.05 \%$ Tricane in $0.003 \%$ PTU and embedded in $1.0 \%$ low melt agarose with their retina facing up. The GFP-labeled nuclei were imaged on a Nikon C1 confocal microscope and image planes were converted from the IDS to ND format using Metamorph Imaging software (Universal Imaging Corp, Philadelphia, PA). Individual image planes were selected for each cell that represented the largest cross-section of its nucleus. Metamorph was then used to measure the cross-sectional area of the individual nuclei $\left(\mu \mathrm{m}^{2}\right)$. Twenty total nuclei from two embryos were analyzed at each time point for both disarrayed and wild-type genotypes.

\section{Time-lapse imaging}

Nuclei of retinal progenitor cells were labeled by microinjection of plasmid DNA encoding the histone2B-GFP fusion protein [48]. Plasmid injection results in mosaic expression of the transgene throughout the embryo allowing for the labeling of only a subset of nuclei within the retina $[49,50]$. All embryos were grown in $0.003 \% 1$-phenyl-2-thiourea (PTU) to block pigmentation and mediate visualization. At $24 \mathrm{hpf}$, labeled embryos were anesthetized with $0.05 \%$ Tricane in $0.003 \%$ PTU and embedded in $1.0 \%$ low melt agarose. Embryos were placed in a glass bottom culture dish and oriented so that the eye was facing up. GFP-labeled cells were imaged on a Nikon C1 confocal microscope. Image planes from confocal microscopy were converted from the IDS to ND format using Metamorph Imaging software (Universal Imaging Corp, Philadelphia, PA). This data was then arrayed by time and $z$ plane using the Multidimensional Analysis Tool Suite. Optical z-sections were collected at $2 \mu \mathrm{m}$ steps every 12 minutes for approximately 24 . Temperature was maintained throughout all experiments at $28.5^{\circ} \mathrm{C}$ using a stage incubator.

\section{Interkinetic nuclear migration velocity measurements}

Individual nuclear of the retina were labeled by microinjection of plasmid DNA encoding the histone2B:GFP fusion protein and by utilizing the $\mathrm{Tg}(\mathrm{h} 2 \mathrm{afz}$ :GFP)kca6 
transgenic line. Embryos were imaged from $24-28 \mathrm{hpf}$ as previously described. Optical z-sections were collected at $1 \mu \mathrm{m}$ steps every 3 minutes for one hour. Metamorph Imaging software was used to measure the distance traveled by individual nuclei. The change in apicobasal distance was then divided by the time that each nucleus was imaged yielding an average velocity measurement of $\mu \mathrm{m} / \mathrm{hr}$. All nuclei that could be tracked within a retinal clone were analyzed. Nuclei from three wild-type and two disarrayed retinas were scored.

\section{Determining the initiation of neurogenesis}

The transgenic line $\mathrm{Tg}$ (elav3:eGFP), provided by Ajay Chitnis (NIH), expresses enhanced green fluorescent protein (eGFP) under the huc promoter was breed into the disarrayed mutant line [30]. To determine when huc:GFP expression is initiated, embryos were treated with PTU and monitored under a fluorescence dissecting scope every 15 minutes beginning at $28 \mathrm{hpf}$. When GFP was visible in the developing retina the embryos were isolated into dishes and phenotyped at $48 \mathrm{hpf}$.

\section{Whole mount in situ hybridization}

Anti-sense cRNA probes were generated for ath 5 mRNA and whole mount in situ hybridization was conducted as previously described with the addition of a final spin column cRNA probe purification using the ProbeQuant G-50 Micro Column (GE Healthcare) [51]. The hybridized probe was visualized using alkaline phosphatase-coupled anti-digoxigenin antibodies and NBT/X-phosphate substrate (Roche). For post-hybridization sectioning, embryos were fixed in $4 \%$ paraformaldehyde/PBS and infiltrated with $15 \%$ sucrose, $30 \%$ sucrose and then 100 $\%$ TBS. Embryos were oriented in a freezing mold and 15 $\mu \mathrm{m}$ sections were cut on a cryostat and mounted on gelatin-coated glass slides.

\section{Genetic mosaics}

\section{Autonomy of delay in histogenesis}

Mosaic retinas were produced by blastomere transplantation [38] and were analyzed for cell autonomy according to established criteria [52]. Clutches of embryos from disarrayed heterozygous matings were dechorionated and injected at the 1-to 4-cell stage with a lineage tracing label (1:9 mix of Texas-Red to biotin-conjugated $10 \mathrm{kDa}$ dextran at a total concentration of $5 \% \mathrm{w} / \mathrm{v}$ (Molecular Probes). At the 1000-cell stage, 5-50 donor cells were transplanted to the animal pole of the dechorionated wild-type hosts, the region fated for eye and forebrain (Kimmel et al., 1995). Donor-host pairs were kept together to ensure correct identification of donor cells. Host embryos were screened at $24 \mathrm{hpf}$ by fluorescence to ensure the incorporation of donor cells within the retina and donor embryos were phenotyped at $48 \mathrm{hpf}$. For assessing cell morphology autonomy, host embryos were fixed at $72 \mathrm{hpf}$ with $4 \%$ paraformaldehyde. Donor cells in host embryos were detected by whole mount immunohistochemistry using streptavidin-HRP and DAB precipitation and then processed for plastic sectioning as described above.

\section{Autonomy of cell cycle exit}

For assessing the autonomy of cell cycle exit delay, mosaic transplantation was performed as described above with the addition of a BrdU injected into the yolk sac of $60 \mathrm{hpf}$ into host embryos. The embryos were then fixed one hour after BrdU injection and processed for BrdU incorporation as described above. Cell cycle exit was quantified by counting the number of BrdU positive cells within each small clone (2-20 cells) (wt in wt $\mathrm{n}=13, d r y$ in wt $\mathrm{n}=8$, $\mathrm{wt}$ in $d r y \mathrm{n}=14$ ). It was necessary to perform an independent experiment to increase the number of mutant into mutant clones because mosaics between heterozygous crosses result in only one in sixteen transplants to be mutant into mutant. To do this, a plasmid encoding soluble green florescent protein (GFP) was used to label small clones of retinal cells. A BrdU injection was preformed on mutant embryos at $60 \mathrm{hpf}$ and these were fixed one hour later and processed as described above $(d r y$ in $d r y \mathrm{n}=10)$.

\section{List of Abbreviations}

$d r y$, disarrayed; hpf, hours post fertilization; dpf, days post fertilization; GFP, green fluorescent protein; ath5, atonal homologue 5 (also referred to as atoh7); pH3, phosphoHistone3; BrdU, 5-bromo-2'- deoxyuridine.

\section{Authors' contributions}

LB carried out all experimentation and drafted the manuscript. BL conceived of the study, and participated in its design, and helped draft and edit the manuscript. Both authors read and approved the final manuscript.

\section{Additional material}

\section{Additional file 1}

Movie of interkinetic nuclear migration in a disarrayed mutant embryo. Images are composed of selected z-planes of H2B:GFP fluorescence in which the monitored cell's nucleus has been pseudo-colored green. The movie plays at 6 frames per second covering 12 hours of development time. Apical and basal surfaces are outlined with dashed red lines in the first frame and developmental time is noted as hours:minutes in the upper right hand corner. Note that only one cell division occurred, denoted at 42:24, during this time-lapse exemplifying the extended cell cycle period. Click here for file

[http://www.biomedcentral.com/content/supplementary/1471213X-7-28-S1.mp4] 


\section{Additional file 2}

Movie of interkinetic nuclear migration in a wild-type embryo. Images are composed of selected compressed z-planes of H2B:GFP fluorescence in which the monitored cells have been pseudo-colored green. The movie plays at 6 frames per second covering 12 hours of development time. Apical and basal surfaces are outlined with dashed red lines in the first frame and divisions are noted in the frame in which they occurred. Developmental time is noted as hours:minutes in the upper right hand corner. Note the rapid nuclear migration and multiple cellular divisions that occurred during this time-lapse.

Click here for file

[http://www.biomedcentral.com/content/supplementary/1471213X-7-28-S2.mp4]

\section{Acknowledgements}

The disarrayed mutation was identified as part of a screen for eye mutations conducted in the Dowling Lab (Harvard University). We gratefully acknowledge Gregory Willer and Ronald Gregg (University of Louisville) for identifying the linked microsatellite marker. This research was supported by a NIH Training Fellowship in Vision Sciences 5T32EY0I4536 (LB), NIH grant R0IEYOI467 (BL) and a March of Dimes Basil O'Connor Fellowship (BL).

\section{References}

I. Turner DL, Cepko CL: A common progenitor for neurons and glia persists in rat retina late in development. Nature 1987, 328: $131-136$.

2. Holt CE, Bertsch TW, Ellis HM, Harris WA: Cellular determination in the Xenopus retina is independent of lineage and birth date. Neuron 1988, I:15-26.

3. Wetts R, Fraser SE: Multipotent precursors can give rise to all major cell types of the frog retina. Science I988, 239: I | 42- I I 45.

4. Dowling JE: The Retina. Cambridge , Belknap; 1987.

5. Ohnuma S, Harris WA: Neurogenesis and the cell cycle. Neuron 2003, 40(2): 199-208.

6. Cepko CL, Austin CP, Yang X, Alexiades M, Ezzeddine D: Cell fate determination in the vertebrate retina. PNAS USA 1996, 93:589-595.

7. Harris WA: Cellular diversification in the vertebrate retina. Curr Opin Genet Dev 1997, 7:65I-658.

8. Hu M, Easter SS: Retinal neurogenesis: the formation of the intial central patch of postmitotic cells. Developmental Biology 1999, 207:309-321.

9. Cremisi F, Philpott A, Ohnuma S: Cell cycle and cell fate interactions in neural development. Curr Opin Neurobiol 2003, I3(I):26-33.

10. Cayouette M, Poggi L, Harris WA: Lineage in the vertebrate retina. Trends Neurosci 2006, 29( 1 0):563-570.

II. Brown NL, Kanekar S, Vetter ML, Tucker PK, Gemza DL, Glaser T: Math5 encodes a murine basic helix-loop-helix transcription factor expressed during early stages of retinal neurogenesis. Development 1998, I 25(23):482 I-4833.

12. Kanekar S, Perron M, Dorsky R, Harris WA, Jan LY, Jan YN, Vetter ML: Xath5 participates in a network of bHLH genes in the developing Xenopus retina. Neuron 1997, 19(5):981-994.

13. Masai I, Stemple DL, Okamoto H, Wilson SW: Midline signals regulate retinal neurogenesis in zebrafish. Neuron 2000 27(2):25I-263.

14. Kay JN, Link BA, Baier $\mathrm{H}$ : Staggered cell-intrinsic timing of ath5 expression underlies the wave of ganglion cell neurogenesis in the zebrafish retina. Development 2005, I32(I I):2573-2585

15. Kim J, Wu HH, Lander AD, Lyons KM, Matzuk MM, Calof AL: GDFII controls the timing of progenitor cell competence in developing retina. Science 2005, 308(5730): $1927-1930$.

16. Brown NL, Patel S, Brzezinski J, Glaser T: Math5 is required for retinal ganglion cell and optic nerve formation. Development 200I, I 28( I 3):2497-2508.
17. Kay JN, Finger-Baier KC, Roeser T, Staub W, Baier H: Retinal ganglion cell genesis requires lakritz, a Zebrafish atonal Homolog. Neuron 200I, 30(3):725-736.

18. Ohnuma S, Hopper S, Wang KC, Philpott A, Harris WA: Co-ordinating retinal histogenesis: early cell cycle exit enhances early cell fate determination in the Xenopus retina. Development 2002, I 29( I0):2435-2446.

19. Takahashi T, Nowakowski RS, Caviness VS Jr.: The cell cycle of the pseudostratified ventricular epithelium of the embryonic murine cerebral wall. J Neurosci 1995, I 5(9):6046-6057.

20. Ohnuma S, Philpott A, Harris WA: Cell cycle and cell fate in the nervous system. Curr Opin Neurobiol 200 I, I I (I):66-73.

21. Lukaszewicz A, Savatier P, Cortay V, Giroud P, Huissoud C, Berland $M$, Kennedy $H$, Dehay $C$ : GI phase regulation, area-specific cell cycle control, and cytoarchitectonics in the primate cortex. Neuron 2005, 47(3):353-364.

22. Calegari F, Huttner WB: An inhibition of cyclin-dependent kinases that lengthens, but does not arrest, neuroepithelial cell cycle induces premature neurogenesis. J Cell Sci 2003, I l 6(Pt 24):4947-4955

23. Calegari F, Haubensak W, Haffner C, Huttner WB: Selective lengthening of the cell cycle in the neurogenic subpopulation of neural progenitor cells during mouse brain development. J Neurosci 2005, 25(28):6533-6538.

24. Link BA, Fadool JM, Malicki J, Dowling JE: The zebrafish young mutation acts non-cell-autonomously to uncouple differentiation from specification for all retinal cells. Development 2000, I27(10):2177-2।88.

25. Perron $M$, Harris WA: Retinal stem cells in vertebrates. Bioessays 2000, 22(8):685-688.

26. Yang Z, Ding K, Pan L, Deng M, Gan L: Math5 determines the competence state of retinal ganglion cell progenitors. Dev Biol 2003, 264(I):240-254.

27. Mu X, Fu X, Sun H, Beremand PD, Thomas TL, Klein WH: A gene network downstream of transcription factor Math5 regulates retinal progenitor cell competence and ganglion cell fate. Dev Biol 2005, 280(2):467-48I.

28. Poggi L, Vitorino M, Masai I, Harris WA: Influences on neural lineage and mode of division in the zebrafish retina in vivo. J Cell Biol 2005, I 7 I(6):99I-999.

29. Masai I, Lele Z, Yamaguchi M, Komori A, Nakata A, Nishiwaki $Y$, Wada $H$, Tanaka $H$, Nojima $Y$, Hammerschmidt M, Wilson SW, Okamoto $\mathrm{H}$ : $\mathbf{N}$-cadherin mediates retinal lamination, maintenance of forebrain compartments and patterning of retinal neurites. Development 2003, I30(I I):2479-2494.

30. Park HC, Kim CH, Bae YK, Yeo SY, Kim SH, Hong SK, Shin J, Yoo KW, Hibi M, Hirano T, Miki N, Chitnis AB, Huh TL: Analysis of upstream elements in the HuC promoter leads to the establishment of transgenic zebrafish with fluorescent neurons. Dev Biol 2000, 227:279-293.

31. Lyons DA, Guy AT, Clarke JD: Monitoring neural progenitor fate through multiple rounds of division in an intact vertebrate brain. Development 2003, I30( I5):3427-3436.

32. Nowakowski RS, Lewin SB, Miller MW: Bromodeoxyuridine immunohistochemical determination of the lengths of the cell cycle and the DNA-synthetic phase for an anatomically defined population. J Neurocytol 1989, 18(3):3। I-3I8.

33. Hayes NL, Nowakowski RS: Exploiting the dynamics of S-phase tracers in developing brain: interkinetic nuclear migration for cells entering versus leaving the S-phase. Dev Neurosci 2000, 22:44-55

34. Willer GB, Lee VM, Gregg RG, Link BA: Analysis of the Zebrafish perplexed mutation reveals tissue-specific roles for de novo pyrimidine synthesis during development. Genetics 2005, I70(4): 1827-1837.

35. Ueno M, Katayama K, Yamauchi H, Nakayama H, Doi K: Cell cycle progression is required for nuclear migration of neural progenitor cells. Brain Res 2006, 1088(I):57-67.

36. Li Z, Hu M, Ochocinska MJ, Joseph NM, Easter SS Jr.: Modulation of cell proliferation in the embryonic retina of zebrafish (Danio rerio). Dev Dyn 2000, 21 9(3):391-40।.

37. Biehlmaier O, Neuhauss SC, Kohler K: Onset and time course of apoptosis in the developing zebrafish retina. Cell Tissue Res 2001, 306(2): 199-207. 
38. Ho R, Kane D: Cell-autonomous action of zebrafish spt-I mutation in specific mesodermal precursors. Nature 1990 348:728-730.

39. Livesey FJ, Cepko CL: Vertebrate neural cell-fate determination: lessons from the retina. Nat Rev Neurosci 200I, 2(2): $109-118$

40. Dyer MA: Regulation of proliferation, cell fate specification and differentiation by the homeodomain proteins Proxl, Six3, and ChxIO in the developing retina. Cell Cycle 2003, 2(4):350-357.

4I. Dyer MA, Livesey FJ, Cepko CL, Oliver G: Prox I function controls progenitor cell proliferation and horizontal cell genesis in the mammalian retina. Nat Genet 2003, 34(I):53-58.

42. Young RW: Cell proliferation during postnatal development of the retina in the mouse. Dev Brain Res 1985, 21:229-239.

43. Alexiades MR, Cepko C: Quantitative analysis of proliferation and cell cycle length during development of the rat retina. Dev Dyn 1996, 205(3):293-307.

44. Nowakowski RS, Caviness VS Jr., Takahashi T, Hayes NL: Population dynamics during cell proliferation and neuronogenesis in the developing murine neocortex. Results Probl Cell Differ 2002, 39: I-25

45. Locker M, Agathocleous M, Amato MA, Parain K, Harris WA, Perron $M$ : Hedgehog signaling and the retina: insights into the mechanisms controlling the proliferative properties of neural precursors. Genes Dev 2006, 20(2 I):3036-3048.

46. Westerfield M: The Zebrafish Book. Eugene, Oregon, University of Oregon Press; 1995.

47. Kimmel CB, Ballard WW, Kimmel SR, Ullmann B, Schilling TF: Stages of embryonic development of the zebrafish. Developmental Dynamics 1995, 203:253-310.

48. Pauls S, Geldmacher-Voss B, Campos-Ortega JA: A zebrafish histone variant H2A.F/Z and a transgenic H2A.F/Z:GFP fusion protein for in vivo studies of embryonic development. Dev Genes Evol 200I, 2I I(I2):603-6I0.

49. Meng A, Jessen JR, Lin S: Transgenesis. In The zebrafish: genetics and genomics Volume 60. Edited by: Detrich HW, Westerfield M, Zon LI. Academic Press; 1999:133-147.

50. Koster RW, Fraser SE: Tracing transgene expression in living zebrafish embryos. Dev Biol 200I, 233:329-346.

5I. Thisse B, Heyer V, Lux A, Alunni V, Degrave A, Seiliez I, Kirchner J, Parkhill JP, Thisse C: Spatial and temporal expression of the zebrafish genome by large-scale in situ hybridization screening. Methods Cell Biol 2004, 77:505-519.

52. Rossant J, Spence A: Chimeras and mosaics in mouse mutant analysis. Trends Genet 1998, 14:358-363.

Publish with BioMed Central and every scientist can read your work free of charge

"BioMed Central will be the most significant development for disseminating the results of biomedical research in our lifetime. "

Sir Paul Nurse, Cancer Research UK

Your research papers will be:

- available free of charge to the entire biomedical community

- peer reviewed and published immediately upon acceptance

- cited in PubMed and archived on PubMed Central

- yours - you keep the copyright
BioMedcentral 